\title{
Design and optimization of the large span dry-coal-shed latticed shell in Liyuan of Henan province
}

\author{
Wenfeng Du*, Chunyu Liu, Yun Sun and Qi Liu \\ Institute of Steel and Spatial Structures in School of Civil Engineering and Architecture, Henan University, Kaifeng \\ 475004 China \\ *Corresponding author: dwf@henu.edu.cn
}

\begin{abstract}
The design and optimization about the large span dry-coal-shed latticed shell in Liyuan of Henan province were studied. On the basis of the structural scheme of double-layer cylindrical reticulated shell, the optimization scheme of the folding double-layer cylindrical reticulated shell was proposed. Through the analysis of a plurality of calculation models, the optimal geometric parameters were obtained after discussing the influence of different slopes of folding lines and shell thickness on the structural bearing capacity and the amount of steel. The research results show that in the case of the same amount of steel, the ultimate bearing capacity of the double-layer folding cylindrical reticulated shell whose folding line slope is $9 \%$ and the shell thickness is about $4.4 \mathrm{~m}$ can be increased $27.3 \%$ compared with the original design scheme.
\end{abstract}

\section{Introduction}

With the expansion of the scale of power plants and environmental protection requirements, the application of dry-coalshed in engineering has been rapidly popularized. Taking into account the needs of practical engineering, dry-coal-shed should have appropriate storage and work space, so the structure should meet the requirements which are large span, high altitude, wide coverage and good mechanical performance. Spatial latticed shell has become the priority structure of dry-coal-shed with the characteristics of large span, good integrated performance and less amount of steel, which has achieved good economic benefits. However, with the dry-coal-shed span requirements rising and the restrictions of steel quantity and safety, the commonly used form of latticed shell structure have already can't meet the demand of practical engineering. It is very necessary to design and optimize the original form of latticed shell structure. Combined with the practical engineering of the large span dry-coal-shed latticed shell in Liyuan of Henan province, the folding doublelayer cylindrical reticulated shell was proposed on the basis of the structural scheme of double-layer cylindrical reticulated shell. In the case of the same amount of steel, the ultimate bearing capacity as the main target optimization function, folding line slope and shell thickness as optimization variables. By optimizing the structure, the optimal structure parameters are obtained.

\section{Engineering situation}

\subsection{Basic situation and structural form selection}

This project is large span dry-coal-shed latticed shell of $33000 \mathrm{Nm} 3 / \mathrm{h}$ coke-oven gas LNG project in Liyuan of Henan province, the main structure is steel material. The structure of the horizontal span is $155.6 \mathrm{~m}$, which is currently the largest span of dry-coal-shed structure over the word. The longitudinal length is $365.82 \mathrm{~m}$, and the vector height is $47.3 \mathrm{~m}$. The height of the dry-coal-shed latticed shell is decided by the coal stacking height and the job requirement of the bucket wheel. In order to ensure the normal operation of the bucket wheel, overall dimension should meet the technological requirements and save space as soon as possible, and the structure as little as possible in contact with both sides of the coals. The dry-coal-shed latticed shell need to meet good mechanical properties, easy manufacture and installation, and the technical and economic indicators superior requirements.

The plane shape of the project is close to a rectangle. Structure shows multi-directional stress characters, planar structure lateral stiffness is weak. Based on the above consideration, the dry-coal-shed latticed shell preliminary adopts the double-layer cylindrical reticulated shell which combines skeletal structures simple structure and shell structure reasonable force characteristics. So the structure has the advantages of beautiful form, low steel consumption, better stiffness and simple force transmission form. The structure is a unidirectional force characteristic when the dry-coalshed latticed shell length and span ratio is more than 1.5 times. Thus the project selection is square pyramid space grids, which can save the amount of steel and enhance the stiffness, so as to realize the purpose of better economic results. 
According to the provisions of "Technical Specification for Space Frame Structures" (JGJ 7-2010) [6], the desirability thickness of the double-layer cylindrical reticulated shell is the width of $1 / 20$ to $1 / 50$, and the preliminary thickness is $4.83 \mathrm{~m}$. The both sides of bottom chord supported in $2 \mathrm{~m}$ height of reinforced concrete columns, and the distance between supports spacing is $10.92 \mathrm{~m}$. The dry-coal-shed profile map and front view as shown in figure 1 and figure 2 .

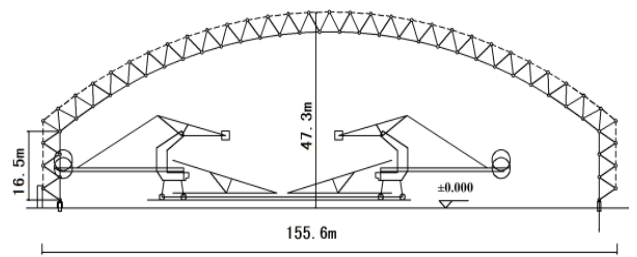

Fig. 1. The profile map of double-layer cylindrical reticulated shell in Liyuan

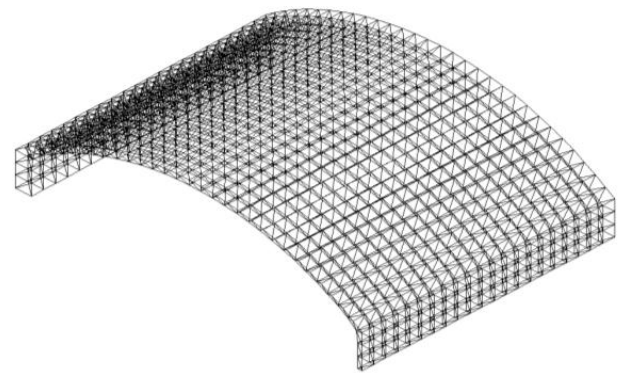

Fig. 2. The front view of double-layer cylindrical reticulated shell in Liyuan

\subsection{Load and their combination}

The dry-coal-shed latticed shell under the main loads include: (1) The constant load: The roof structure using single profiled steel sheet and purlin (excluding net weight), load is $0.25 \mathrm{KN} / \mathrm{m} 2$; (2) The roof uniformly distributed live load: Taking into account the local snow load, roof live load is $0.5 \mathrm{KN} / \mathrm{m} 2$ from live load and snow load maximum which apply in the first quarter node; (3) The wind load: The basic wind pressure is $0.55 \mathrm{KN} / \mathrm{m} 2$ ( 100 years return period), and the surface roughness is class B; (4)The earthquake: The seismic fortification intensity is 8 degrees, and the design of earthquake acceleration is $0.2 \mathrm{~g}$. The classification of design earthquake is the first group, the building site categories is class II, and the building seismic fortification type is class C; (5) The temperature difference: Local basic temperature from -8 to $36^{\circ} \mathrm{C}$, so the temperature difference is \pm 30 degrees when design the structure, requiring joining temperature from 6 to $22^{\circ} \mathrm{C}$. Based on "Load code for the design of building structures" (50009-2012 GB) carry the load combination [7], and the load combination analysis is carried by MSTCAD, then calculate and analysis 19 kinds of working conditions combination. This paper takes the most unfavorable load combination to optimize: 1.2 static +1.4 live $=1 \mathrm{KN} / \mathrm{m} 2$.

\subsection{Design parameters}

(1) The material: The material of steel pipe, sealing plate and cone-shaped connectors all select the Q345B, and design strength is $315 \mathrm{~N} / \mathrm{mm}^{2}$. High-strength bolt using $40 \mathrm{Cr}$ or $20 \mathrm{MnTiB}$. Bolt sphere select 45 steel.

(2)The deflection limit value: Considering large deformation will affect the drainage and safety of the structure, so "Technical Specification for space Frame Structures" (JGJ7-2010) requirements structure deflection span ratio is L/250 ( $\mathrm{L}$ is the span) and the displacement limit value is $0.6224 \mathrm{~m}$.

(3)The slenderness ratio: The lever limit slenderness ratios are determined by "Technical Specification for space Frame Structures" and "Code for seismic design of Buildings" (GB50011-2010) [8]. For compression member, the limit slenderness ratios is mainly to prevent too thin prone to bend, thereby affecting the ultimate capacity of compression bar, so limit slenderness ratio is 150 ; for tension member, the allowable slenderness ratio is mainly to ensure the lever in the production, transportation, installation and use of the process with a certain stiffness, so the limit value is 250 ; the bar where near the support may be affected by impact or supports uneven settlement, leading to the phenomenon of corrosion, bending, stress complex. The bar near the support is a sensitive area where affect the safety of the structure, 
so the limit slenderness ratios of the web member near the support are 150, which are the same as the limit slenderness ratios of the compression member.

(4)Stress ratio: The seismic code provisions the seismic combined internal force value of the key member in the 8 degree area should multiplied by the coefficient of 1.15 . The general stress ratio limit is 0.9 , so the control key bar stres $s$ ratio limit is 0.8 .

\subsection{Structure basic characteristics analysis}

(1) Firstly, the structure is analysed and designed with MSTCAD, and the design stress is $283.5 \mathrm{~N} / \mathrm{mm} 2 \mathrm{which}$ strength design value of $90 \%$. The structure is applied load and full stress automatic optimization calculation is carried out, adjusting the software auto-configuration of the rods. The member section too small to be easy to produce the initial bending, taking into account the convenience of welds and anti-corrosion requirements. The wall thickness of circular steel tube should not be too thin, increasing the key parts of the member section properly, to strengthen the selfsupporting performance of the shell. The final selection of the rod specifications has 10 species: $\varnothing 60.0 \times 3.50$ 、 $\emptyset 89.0 \times 4.00 、 \emptyset 114.0 \times 4.0 、 \varnothing 140.0 \times 6.0 、 \varnothing 159.0 \times 6.0 、 \varnothing 180.0 \times 12.0 、 \emptyset 219.0 \times 14.0 、 \emptyset 219.0 \times 16.0 、 \emptyset 245.0 \times 16.0 、$ $\emptyset 299.0 \times 22.0$. The biggest bar in superior string layer edge arch part, inferior string layer maximum bar specifications is $\emptyset 219.0 \times 14.0$, web members selection bar specifications smaller. The steel consumption of the main structure (not counting node weight) is $809.36 \mathrm{t}$. The overall displacement of the structure is shown in Figure 3, and the maximum displacement is $0.511 \mathrm{~m}$, to meet the specifications of the design requirements. The maximum stress is $279.8 \mathrm{~N} / \mathrm{mm} 2$, which is less than control stress. The results of MSTCAD analysis show the strength and stiffness of the structure meet the requirements of the specification.

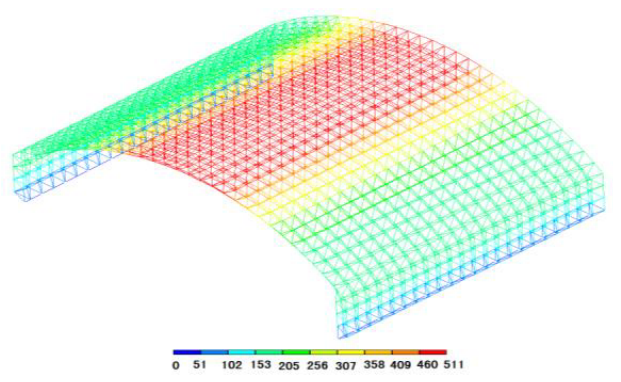

Fig. 3. The displacement diagram of Structure

(2) The structural model is input to the general finite element software ANSYS, carrying the eigenvalue buckling analysis [9], and obtain buckling mode and eigenvalues coefficient, as shown in Figure 4. As can be seen from the results of the analysis, the first order modal along the arch to the buckling of single-wave anti-symmetric, the first order eigenvalue coefficient is 10.459 . In order to more accurately reflect the real structure of the large deformation, to carry the geometrically nonlinear analysis, as shown in Figure 5. The structure of the nonlinear buckling load is $1.339 \mathrm{KN} / \mathrm{m} 2$. It is the weak link where structure across the region. Comparison of eigenvalue buckling analysis and geometric nonlinear analysis shows the buckling load of the latter is smaller than that of the former obviously, so the geometric nonlinear analysis of the structure is very necessary.

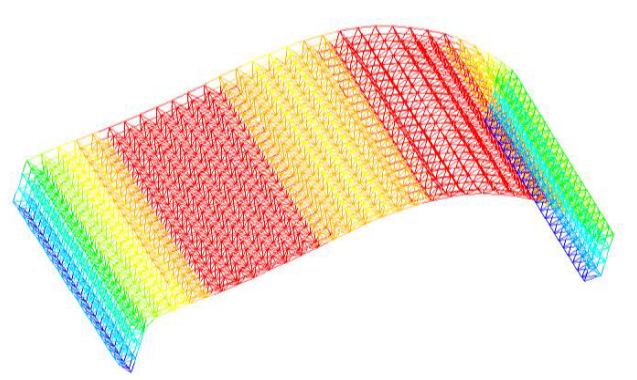

Fig. 4. The integral displacement of the first mode

(3) By checking the strength, rigidity and stability of the structure, we can obtain the following conclusions. Although they all meet the requirements, the structural geometric nonlinear buckling load is 1.339 times larger than the design load value. It is too small to cause the structure of the stability safety factor is small. The structure may be unstable failure if the structure is subjected to the load limit. Based on the above analysis, it is necessary to optimize the shell, achieve the purpose which the ultimate bearing capacity promotion in case of the same amount of steel. 


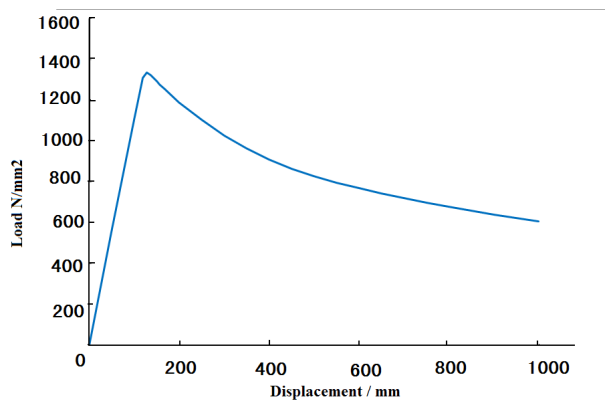

Fig. 5. Structural load displacement curve and failure mode

\section{Optimizing Design}

\section{1 optimization method}

Double-layer cylindrical reticulated shell structure by the action of "thin film" as the main force characteristic, most of the load are transmitted by the shell member axial force form, structure vertical stiffness is weak, and bending stiffness is small, greatly reduce the carrying capacity of the latticed shell structure. With the increase of the structure span, the safety defects of the double-layer cylindrical reticulated shell structure are more and more obvious, and the structure prone to damage.

Structural flexural rigidity is proportional to the third power of the thickness, folding the double-layer cylindrical reticulated shell plane, so that the structure is formed polygonal-shape reticulated shell along the longitudinal direction line, forming in transverse ridges and valleys. This method is equivalent to increasing the equivalent thickness of the structure, and the optimized structure is called as the folding double-layer cylindrical reticulated shell structure. The shape characteristics of the structure: the cross-section remains cylindrical form, but the form of a longitudinal cross section of a line, as shown in Figure 6.

In this paper, the flexural rigidity of the folding double-layer cylindrical reticulated shell structure is large, which can overcome the low of the vertical stiffness and the defects of the bearing capacity. In the optimization design, all folding line slope were optimization analysis firstly, and choose the optimal linear slope, then based on the influence of shell thickness on the structure performance, quadratic optimization of structure is carried, summary and analysis to determine the best structure selection.

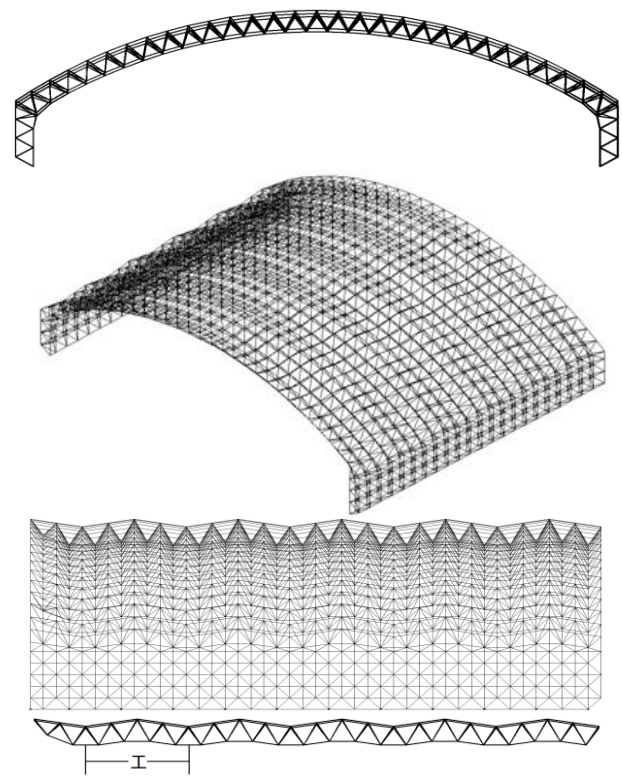

Fig. 6. (a) Cross section of the folding double-layer cylindrical reticulated shell; (b) The axis of the folding double-layer cylindrical reticulated shell; (c) the vertical elevation and section of the folding double-layer cylindrical reticulated shell 


\subsection{Optimization analysis of line slope}

In the full stress design, changing the size of the rod size, to ensure that each calculation model is close to the amount of steel 。 According to the size of the $\mathrm{h}$ divide into six groups, respectively, $1 \mathrm{~m}, 1.2 \mathrm{~m}, 1.4 \mathrm{~m}, 1.6 \mathrm{~m}, 1.8 \mathrm{~m}, 2.0 \mathrm{~m}$. Geometric nonlinear analysis is carried out, and the displacement contour and the load displacement curve are observed and compared with the ultimate load bearing capacity.

Figure 7 is a geometric nonlinear analysis results which seven kinds of the folding double-layer cylindrical reticulated shell structure. From the load displacement curve, it can be seen that the structure has obvious geometric nonlinearity. Taking into account the different $\mathrm{h}$ values corresponding to the instability mode map is similar, so only the results of the geometric nonlinear analysis of the folding double-layer cylindrical reticulated shell structure in $\mathrm{h}=1.0 \mathrm{~m}$ is listed, as shown in Figure 9.The results of seven kinds of the folding double-layer cylindrical reticulated shell structure with steel, maximum displacement and ultimate bearing capacity are summarized as shown in table 1.

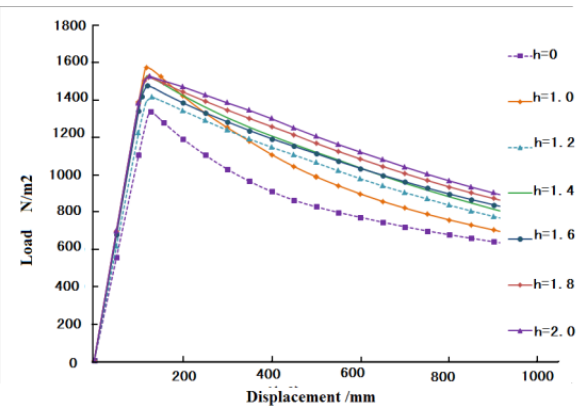

Fig.7. Different slopes corresponding structural load displacement curve

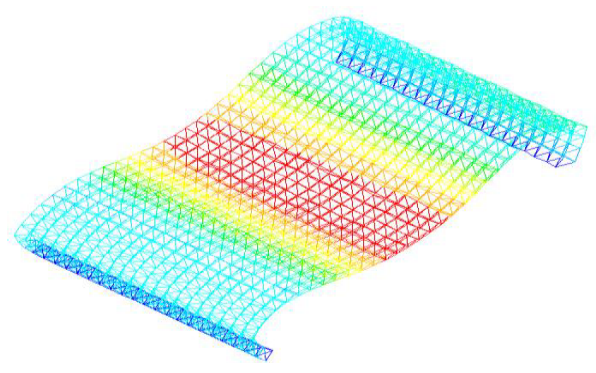

Fig.8. The structural instability mode figure when $\mathrm{h}=1.0 \mathrm{~m}$

Table 1. H1 H6 of different curves

\begin{tabular}{|c|c|c|c|}
\hline $\mathrm{h} / \mathrm{m}$ & The amount of steel $/ \mathrm{t}$ & Maximum displacement $/ \mathrm{m}$ & Ultimate bearing capacity $\mathrm{KN} / \mathrm{m}^{2}$ \\
\hline 0 & 809.36 & 0.572 & 1.339 \\
\hline 1.0 & 809.21 & 0.401 & 1.578 \\
\hline 1.2 & 809 & 0.406 & 1.421 \\
\hline 1.4 & 809.20 & 0.4 & 1.540 \\
\hline 1.6 & 808.92 & 0.4 & 1.493 \\
\hline 1.8 & 809.55 & 0.391 & 1.528 \\
\hline 2.0 & 809.20 & 0.387 & 1.575 \\
\hline
\end{tabular}

Comprehensive chart results can be obtained, the ultimate bearing capacity is the largest when $\mathrm{h}=1.0 \mathrm{~m}$ (line slope is $9.16 \%$ ), and the value is $1.578 \mathrm{KN} / \mathrm{m}^{2}$. Compared to the double-layer cylindrical reticulated shell in its bearing capacity increase $17.91 \%$, at the same time the structure of the maximum stress is $262.4 \mathrm{~N} / \mathrm{mm}^{2}$ and the maximum vertical 
displacement is $0.401 \mathrm{~m}$, the strength, stiffness and stability of the structure are improved significantly. The ultimate bearing capacity of the structure is the lowest bearing capacity of the structure with the change of the slope of the line when the $\mathrm{h}=1.2 \mathrm{~m}$, and the value is $1.42 \mathrm{KN} / \mathrm{m}^{2}$. However, the ultimate bearing capacity of the structure increased $5.97 \%$ compared to the original double-layer cylindrical reticulated shell, at the same time the structure of the maximum stress is $288.8 \mathrm{~N} / \mathrm{mm}^{2}$ and the maximum vertical displacement is $0.406 \mathrm{~m}$, the strength, stiffness and stability of the structure are improved significantly. The analysis results show the ultimate bearing capacity of the double-layer cylindrical reticulated shell structure can be significantly improved by changing the line slope, so this optimization method is feasible and effective. The appropriate line gradient is $\mathrm{h}=1.0 \mathrm{~m}$ (the line slope is $9.16 \%$ ).

\subsection{Optimization analysis of shell thickness}

On the basis of the optimization in the line slope, the shell what the $\mathrm{h}=1.0 \mathrm{~m}$ and the shell thickness $\mathrm{H}=4.83 \mathrm{~m}$ is selected to make the quadratic optimization. In the case of the same amount of steel, the shell thickness is an important factor to affect the bearing capacity. Use different shell thickness in this project, to analysis the impact of different shell thickness $\mathrm{H}$ on the structure bearing capacity. The results of different shell thickness with steel, maximum displacement and ultimate bearing capacity are summarized as shown in table 2 . The influence of shell thickness on the bearing capacity can be directly seen through the different shell thickness $\mathrm{H}$ corresponding to bearing capacity curve, as shown in Figure 9.

Table 2. The data comparison of the different shell thickness

\begin{tabular}{|c|c|c|c|}
\hline $\begin{array}{c}\text { Shell } \\
\text { thickness } \\
/ \mathrm{m}\end{array}$ & $\begin{array}{c}\text { The } \\
\text { amount of } \\
\text { steel } / \mathrm{t}\end{array}$ & $\begin{array}{c}\text { Maximum } \\
\text { displacement } \\
/ \mathrm{m}\end{array}$ & $\begin{array}{c}\text { Ultimate bearing } \\
\text { capacity } \mathrm{KN} / \mathrm{m}^{2}\end{array}$ \\
\hline 3.0 & 809.28 & 0.595 & 1.135 \\
\hline 3.5 & 809.00 & 0.514 & 1.284 \\
\hline 4.0 & 809.70 & 0.457 & 1.479 \\
\hline 4.4 & 808.78 & 0.422 & 1.705 \\
\hline 5.0 & 809.74 & 0.393 & 1.657 \\
\hline 5.5 & 808.41 & 0.372 & 1.630 \\
\hline 6.0 & 809.25 & 0.367 & 1.534 \\
\hline
\end{tabular}

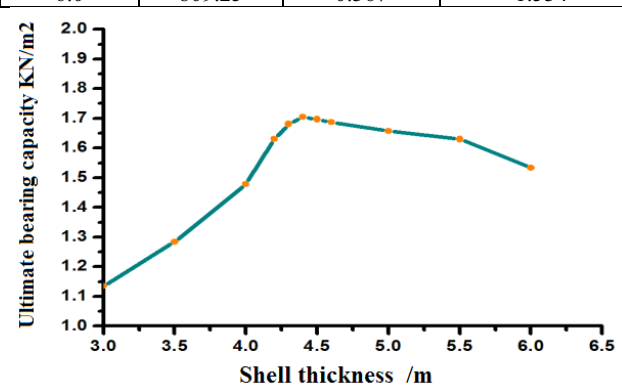

Fig.9. Different shell thickness corresponding bearing capacity curve

From table 2, figure 9 shows that shell thickness and ultimate bearing capacity has generally increased first and then decreased. The ultimate bearing capacity is the largest when the shell thickness $\mathrm{H}=4.4 \mathrm{~m}$, the value is $1.705 \mathrm{KN} / \mathrm{m} 2$, bars maximum stress $248.5 \mathrm{~N} / \mathrm{mm} 2$, and the maximum vertical displacement of $0.512 \mathrm{~m}$. Compared to the structure of the front of the quadratic optimization, its strength and stability has significantly improved, so this optimization method is proved feasible and effective.

\subsection{Optimization results}

Through the structure optimization, then determine the structure type selection is folding double-layer cylindrical reticulated shell, the shell thickness is $4.4 \mathrm{~m}$ and the line slope is $9 \%(\mathrm{~h}=1.0 \mathrm{~m})$. In the case of the same amount of steel, the ultimate bearing capacity of the shell what is optimized enhance $27.33 \%$ than the initial model, the maximum stress of the rod is reduced $11.19 \%$, and the maximum vertical displacement of the structure can meet the requirements of the specification.

The final choice of rod specifications has nine species: $\varnothing 89.0 \times 4.00 、 \emptyset 114.0 \times 4.0 、 \emptyset 140.0 \times 6.0 、 \emptyset 159.0 \times 6.0$ 、 $\emptyset 180.0 \times 12.0 、 \emptyset 219.0 \times 14.0 、 \varnothing 219.0 \times 16.0 、 \emptyset 245.0 \times 16.0 、 \varnothing 299.0 \times 22.0$. The biggest bar in superior string layer edge arch part, inferior string layer maximum bar specifications is $\emptyset 180.0 \times 12.0 \mathrm{~mm}$, web members selection maximum bar specifications is $\emptyset 159.0 \times 6.0 \mathrm{~mm}$, and the number of units is 6048 . The steel consumption of the main structure is $808.78 \mathrm{t}$. 


\section{Conclusion and suggestion}

(1)The large span dry-coal-shed latticed shell in Liyuan use the optimized structural which the folding double-layer cylindrical reticulated shell has obvious advantages than double-layer cylindrical reticulated shell. The ultimate bearing capacity of the double-layer folding cylindrical reticulated shell can be increased $27.3 \%$ compared with the original design scheme, and increase economic efficiency.

(2)For the folding double-layer cylindrical reticulated shell, the strength, stiffness and stability are better when the line slope is $9 \%$ and the shell thickness is about $1 / 35$ of span.

(3)In the construction of the folding double-layer cylindrical reticulated shell, along the longitudinal direction can take a fold line as the basic unit for installation, and finally connected with each fold line which between the bottom chord bar.

\section{References}

1. H. Deng, S.L. Dong, Shape optimization of spatial latticed shell structures, Journal of Zhejiang University(Engineering Science), 33,371(1999)

2. L.Y. Shan, H. Yan, Optimization analysis of large-span double-layer cylindrical latticed shell structure,20,47(1999)

3. Z.F. Liu, Z.T. Yan, Scheme selection and optimum design of single-layer reticulated domes, Journal of Civil, Architectural \& Environmental Engineering,29,83(2007)

4. Y.M. Li, Y.G .Zhang, Section optimization of cable-supported latticed shell, Industrial Construction, 37, 73( 2007)

5. Y.Q. Qi, Optimization design of large-span spatial latticed, Construction Technology, 38,393( 2009)

6. Technical Specification for space Frame Structures: JGJ7-2010[S]. Beijing: China Architecture \& Building Press, 2010

7. Load code for the design of building structures:GB 50009-2012. Beijing: China Architecture \& Building Press, 2012

8. Code for seismic design of Buildings: GB50011 - 2010. Beijing: China Architecture \& Building Press,2010

9. J.G. Zhang, Z.Z. Fan, S.Y. Liu, Optimization design for large span dry-coal-shed latticed shell in Xiangfan power plant, Building Structure, 39,378(2015)

10. Y. G, H. Chen, H.F Yu, Structural design and analysis on the large- span dry coal shed in a thermo power station, Building Structure, 45,49(2015) 